\title{
The University as Meeting Place
}

\section{Stewart Motha ${ }^{1}$}

Accepted: 23 May 2021 / Published online: 23 June 2021

(c) The Author(s), under exclusive licence to Springer Nature B.V. 2021

\begin{abstract}
The space, work, and pedagogy of universities have undergone rapid and unprecedented change during the Covid pandemic. These developments have been heralded as marking the emergence of a 'new normal'. Reflecting on the unique aspirations and utopian sense of universities, I give an account of the political stakes at a time of fundamental change. I also provide a brief introduction to the other essays in this Supplement.
\end{abstract}

Keywords Galtha $\cdot$ Meeting $\cdot$ Pandemic $\cdot$ University $\cdot$ Work

Back in the 1990s, I worked as a Legal Officer and Native Title Case Manager at the Aboriginal Legal Rights Movement (ALRM) in South Australia. A community hub of legal aid and activism, the organisation has represented indigenous people in that state since the 1960s; and it is managed and run by Aboriginal people. When the era of recognition through native title commenced after the decision of the High Court of Australia in Mabo v Queensland (1992), ALRM represented applicants in the South Australian native title test-case, and coordinated the mediation of overlapping claims. I recall this time now as doing this work gave me a potent sense of an otherwise prosaic aspect of social and political life: what it means to come together in a meeting. While who would attend a meeting was sometimes hotly contested, there was no question that a meeting concerning Aboriginal land and waters needed to occur in the right place. It was not uncommon to drive vast distances over several days in order to meet and discuss matters with the right people in the right place: that is, in country. Aboriginal ritual and law determined the possibility and meaning of meetings. To come together, receive instruction, discuss disputes, to learn and to share - these were the hallmarks of a meeting that would in time be regarded as an event. I recall this now as it seems so thoroughly apt for considering the place and character of the university as the site of a particular kind of work, dialogue, and public life.

Stewart Motha

s.motha@bbk.ac.uk

1 School of Law, Birkbeck, University of London, Malet Street, London WC1E 7HX, UK 
What is a university - as space of encounter, ethos of engagement, and pedagogic practice? What does it mean to work in a university, especially now, in the time of the Covid-19 pandemic? These questions are provoked by the proliferation of talk of a 'new normal' in modes of teaching, and for disseminating and discussing research. The fact that academics moved teaching and symposia online at a rapid and unprecedented scale has fuelled claims that cultures and practices of work at universities have fundamentally shifted. More wide-ranging claims are being made about how all 'office' work will move to hybrid combinations of home-working with attendance in urban centres becoming sporadic (Seabrook 2021). Some of this hyperbole is merely catching up after the event. Most academics in the humanities and social sciences in particular have long enjoyed the luxury of combining working from home with attendance on campus to teach and meet colleagues. But there can be no doubt that this 'mixed mode' will be standardised in processes that consolidate the move online and reflect palpable shifts in how academics and students want to live, work, and study.

Advocates of more remote working-teaching-learning claim that the pandemic has ushered in greater accessibility, cut out travel times, and enabled more fluid global connectivity. The rapid move to teach university courses online, convene scholarly symposia on platforms such as MS Teams, Zoom, and other virtual meeting places is being treated as a great leap forward for tertiary education and global intellectual collaboration. For those more sceptical about these developments - among whom I count myself - the university stands for something that cannot be reduced to a mode of communication, the numbers that attend an online class, or journey times. This is not to say that there is some ideal 'golden age' of the university to be preserved, or that the enhancements of online learning do not offer significant benefits. It is, rather, to pose the question about the place of the university as a social formation - one that constitutes society as much as reflects its many tensions and contradictions.

Virtual learning environments (VLEs), enhanced by online access to libraries, e-books, pre-recorded lectures, podcasts, and 'live' video conferences certainly helped to ensure continuity of teaching and learning in conditions of a global health emergency. I have taken to podcasting myself through Countersign, ${ }^{1}$ although this was planned in advance of the pandemic with a commitment to reach audiences beyond the usual bounds of academic publishing. Despite the technological leaps that have been made in the face of this recent adversity, we should ask what the deeper and enduring impact will be of remote online teaching/meeting for the work of universities. I am especially concerned here about the impact of the 'online revolution' for the university as the harbour, sanctuary, and site of the humanities.

\footnotetext{
1 Visit https://countersignisapodcast.com; and available on iTunes, Spotify, and wherever you get your podcasts.
} 


\section{Virtual Work}

In the 'University Without Condition', an immensely prescient lecture that Jacques Derrida gave in 1999, he characterised the university as the place where nothing should be beyond question (Derrida 2002). He expressed a spirit of openness and refused boundaries, especially in relation to what can be said and thought. In doing so Derrida was connecting to a freedom rooted in the Enlightenment that helped to constitute a particular idea of the public:

Here, then, is what we could call, in order to call upon it, the unconditional university or the university without condition: the principle right to say everything, even if it be under the heading of fiction and the experimentation of knowledge, and the right to say publicly, to publish it. This reference to public space will remain the link that affiliates the new Humanities to the age of Enlightenment. It distinguishes the University institution from other institutions founded on the right or the duty to say everything, for example, religious confession and even psychoanalytic 'free association'. (2002, p. 205)

A boundless university is, of course, an injunction that may also be called on by those who see the rapid and comprehensive move to online teaching as part of a drive for invention, democratisation, expanding reach, accessibility, and massification. The 'right to say everything', yes, but then why not the ability to say it through a multiplication of platforms (in person or virtual), times (synchronous and asynchronous), and modes of delivery (every week over an academic year, intensively, and everything in-between)?

The Covid-19 pandemic has enabled a sharper view of the double-bind of a 'university without condition'. The spirit of unboundedness upon which the university stands exposes a flip side to which its occupants are often blind. The material conditions of production and re-production determine all forms and practices of life. What if there is nothing unique about the space and place of a university? It is then exposed to all of the ecotechnic forces that drive social formations. How, then, can the claim be sustained that the university stands for something that is, and ought to be, immutable? Indeed, even elevating the university as an unconditional site, proceeding as if it is without condition, exposes it to the dangers of having no alignment or ethos to defend.

Derrida was not blind to the potential effects of technologically enhanced communication, and its impact on the work of universities. The technological accelerations that have been observed during the time of the Covid pandemic need to be placed alongside the already emergent transformations in the 'stage of virtualization' which requires that what is possible, and even the boundaries of disciplinary fields, be rethought. We find ourselves not in:

a virtual politics but a politics of the virtual in the cyberspace or cyberworld of worldwide-ization. One of the mutations that affect the place and the nature of university work today is a certain delocalizing virtualization of the space of communication, discussion, publication, archivization. [...] What is new, quantitatively, is the acceleration of the rhythm, the extent, and the powers of 
capitalization of such a virtuality. Hence the necessity to rethink the concepts of the possible and the impossible. This new technical 'stage' of virtualization (computerization, digitalization, virtually immediate worldwide-ization of readability, telework, and so forth) destabilizes, as we have all experienced, the university habitat. It upsets the university's topology, disturbs everything that organises the places defining it, namely, the territory of its fields and its disciplinary frontiers as well as its places of discussion, its field of battle, its Kampfplatz, its theoretical battlefield - and the communitary structure of its 'campus'. (2002, p. 210)

But this new technical stage is not benign in the sense of being merely enabling. The loss of the 'local' is also the loss of ritual and comportment. The solemn silence when passing through the threshold of a library; the negotiation of space when entering a lecture theatre; the solidarity and annoyance after a heated debate which must pass into some other social exchange when leaving the classroom - these are physical encounters that are lost with virtualization. A digitally recorded lecture can be copied across platforms, courses, spaces - and is archived at the moment of production. This paradoxically enables infinite memory and becomes instantly forgettable. The erosion of contact in a physical space also marks the end of the political occupations that have launched so many resistance movements.

\section{Walls for Meeting}

I cannot help thinking, as I look at a computer screen that serves as a portal to teaching students or meeting colleagues, that I am looking at a wall - only, it is the wrong kind of wall. In one sense a computer screen is a permeable barrier that has enabled communication and continuity of work during a pandemic that required isolation and social distancing. To understand why it is the wrong kind of wall, we need to explore walls as enabling dialogue, ritual, and the creation of meaning and sense. This may seem counter-intuitive at a time when walls are associated with borders to keep out migrants and separate peoples.

Paul Carter's evocative collection of essays, Meeting Place: The Human Encounter and the Challenge of Coexistence, refers to Franz Kafka's suggestion that walls should be built across the large and unfriendly squares in Vienna (Carter 2013, p. 173). The wall invoked here is not a barrier but a 'handrail'; an 'edge' that provides a 'helping hand' in crossing what would otherwise be an ungraspable void (2013, p. 173). Carter also draws on Arrernte and other Central Australian indigenous peoples' understanding of the preconditions for meeting, exchange, and translation: 'their places are represented by concentric circles, as if meeting consisted in breaching one wall after another' (2013, p. 175). He recalls the Yolngu Garma festival in Arnhem land - a space set aside for education:

For Garma to become an event place 'where ideas are shared and negotiated in order to facilitate agreement', there needs to be an intensification of interests and alignment. This notion is conceptualised in the Yolngu term galtha: a 'Connecting spot ... a spot where people make solid contact with the earth, 
when they have been brought together from different places, and now they are having a discussion together to agree on a plan of action. Anywhere there is ceremony, there will be galtha'. (2013, p. 177)

These connecting spots where contact is made are a condition of ceremony. It is with ceremony that an intensification of interests and focused attention to agree action can emerge. What can be drawn from this in the context of the university?

One of the key things lost in the move to teaching-learning online is the sense of uniqueness in attending a place called university. If universities are places where social capital is exchanged (and more recently there has been an expansion and democratization of this good), the distinctness of the encounter on site matters. There is little to distinguish the 'live' online teaching session or a pre-recorded lecture from a TED Talk. Why does this matter? While group work and collaborative endeavours are possible online - learning has become an individualistic rather than collective endeavour. Argument and compromise, tension and resolution - and the inevitable impasse and irresolution - have a different inflection when they are experienced in person. The affective dimension of learning-together comes from a comportment and disposition specific to the physical space of the university. How do I know this? Can we not all argue and disagree online? Here the Yolngu notion of galtha is useful - and it also suggests that this is not merely about the privileged place of the university. The intensification and alignment of interests can come through the 'journey to ...' Time needs to be taken and given, first to one-self, in order to attend a place of learning or ceremony, or indeed a theatre, doctor, mosque, synagogue, or church with their rituals of coming and going, profane and sacred encounters. A journey takes time - and being 'time poor' has come to justify the sense that 'logging-in' to a computer creates more access to education. But taking time - carving out the space for learning, thinking, and action - is distinctly public and political. The university is this public and political space that must not be desiccated as the object of infinite consumerist choices. In this space of intensification, alignment, and action we get a glimpse of what society might be. Let us keep this handrail in the void. Now, draw and hold the line!

The essays gathered in this Supplement of Law \& Critique about what has been termed the 'new normal' take up the question of what being public, political, and holding things in-common during the time of a global pandemic means. Stephanie Jones evocatively moves us through the contours, hues, and assemblages of human and non-human life. Her neighbourhood Common is an intimate space to be shared with the Great Crested Newt. But what are the conditions of this sharing of space? Our homes are now (over)used as workspaces, invading the quiet time of the cats who really need their own time. What mutuality is possible, as Elena Loizidou also asks, in forms of life, human or animal? Contrary to what the theorists of power, norms, and the 'normal' may hold, intimately connected material worlds of ecologies have always managed mutual aid. As Oscar Guardiola-Rivera argues in his account of 'lawfare', the law and governing by numbers can achieve what was otherwise pursued by military and commercial means. There is hope, however, in making 
kin, staying with the problem, through speculative fictions, feminisms, and ethnographies. Adam Gearey sharpens the pen and crystalises the political-economy of travel time as dead time, working in the bedroom, and shopping from your kitchen table. Hold on, he says! The house is the place where one dreams. The mind needs time to wander; the time between travelling to meetings.

\section{References}

Carter, Paul. 2013. Meeting place: The human encounter and the challenge of coexistence. Minneapolis: University of Minnesota Press.

Derrida, Jacques. 2002. The university without condition. In Without alibi, trans. and, ed. J. Derrida and P. Kamuf. Redwood city: University of Stanford Press.

Seabrook, John. 2021. Has the pandemic transformed the office forever? The New Yorker, 25 January. https://www.newyorker.com/magazine/2021/02/01/has-the-pandemic-transformed-the-office-forev er. Accessed 22 May 2021.

Publisher's Note Springer Nature remains neutral with regard to jurisdictional claims in published maps and institutional affiliations. 